\title{
Enrique Granados en París: la construcción de un icono español en el ámbito musical internacional
}

\author{
Miriam Perandones
}

\section{Resumen}

La relación de Granados con París plantea varios interrogantes al investigador que se acerca a estudiar la vida de este compositor. Al contrario de lo que podría parecer, Granados no aparece en la prensa musical francesa hasta los últimos años de su vida mientras otros intérpretes españoles, como su íntimo amigo Ricardo Viñes o Pablo Casals, en 1900 ya son intérpretes reconocidos o aparecen asiduamente en los conciertos parisinos.

Ante este hecho inmediatamente surge una pregunta: por qué Granados, una de las figuras universales del nacionalismo español junto a Isaac Albéniz y Manuel de Falla, falta en la prensa especializada de París hasta prácticamente 1909, apenas seis años antes de su muerte.

En este artículo pretendemos explicar la relación de Granados con la ciudad y las razones por las cuales encuentra un éxito internacional tardío, pero que le convierte en un icono nacionalista español y universal. Se ha realizado a partir de una recopilación sistemática de la prensa ${ }^{1}$, estudiando por qué aparece Granados en la vida musical parisina y cómo recibió Francia su obra. El trabajo se completa con la revisión del epistolario inédito de Granados, elaborado en nuestra tesis doctoral2 ${ }^{2}$.

El compositor residió casi dos años en París entre 1887 y 1889 como alumno de piano del importante profesor Charles de Bériot. Veinte años más tarde, Granados orientaría su llegada a París primero como intérprete (1909) y después como compositor (1911 y 1914) buscando el reconocimiento internacional.

Palabras clave: Granados, París, crítica, Goyescas, nuevo españolismo.

\footnotetext{
${ }^{1}$ Existe una transcripción de fragmentos de algunos artículos en Enrique Granados. Algunas opiniones de prensa sobre sus conciertos. Musicografía Wagner. Barcelona: Tipografía "La Moderna". 191-.

${ }^{2}$ La canción lírica de Enrique Granados (1867-1916): microcosmos estilístico elaborado a partir de un nuevo epistolario. Tesis inédita. Departamento de Historia del Arte y Musicología de la Universidad de Oviedo, 2008.
} 


\section{Abstract}

The Granados' relation with Paris raises several questions to any researcher who studies the composer's life. Unlike what might seem, Granados does not appear in the musical French press until his last years, while other Spanish performers, as his intimate friends Ricardo Viñes or Paul Casals, are already recognized players or appear frequently in the Parisian concerts in 1900.

In view of this situation a question arises immediately: why Granados, one of the universal figures of the Spanish nationalism together with Isaac Albéniz and Manuel de Falla, missed in the specialized press of Paris until 1909, just six years before his death.

In this article I am going to explain the relation of Granados with this city and why he achieved an international success, even though it was rather late. However, this achievement turned him into a universal and Spanish icon. This work has been done from a systematic summary of the press to clarify how France received his work and answer these questions. This article is completed with a revision of the unpublished collected letters of Granados, a part of my doctoral thesis.

This composer lived for almost two years in Paris between 1887 and 1889 . He was a pupil of the important piano teacher Charles de Bériot. Twenty years later, Granados appeared in Paris as a piano performer (1909) and later as a composer (1911 and 1914). He was looking for the international recognition.

Key words: Granados, Paris, review, Goyescas, new musical Spanishness.

\section{Estancia y formación $(\mathbf{1 8 8 7 - 1 8 8 9})^{3}$}

La etapa de formación en París es un apartado vital con muchas sombras que hasta ahora se conocía principalmente a partir de la detallada descripción que realiza Ricardo Viñes en la Revista Musical Hispano-Americana ${ }^{4}$. En este trabajo hemos completado el relato biográfico a partir de la tesis doctoral de Nina Gubisch sobre el

\footnotetext{
${ }^{3}$ Para una revisión más detallada consúltese nuestra tesis doctoral La canción lírica... Ibídem. ${ }^{4}$ VIÑES, Ricardo. "Granados íntimo o Recuerdos de su estancia en París" Revista Musical HispanoAmericana, 31 de agosto de 1916
} 
diario de este intérprete leridano ${ }^{5}$ y de la revisión de documentos oficiales del Conservatorio de París.

Granados es uno más de los jóvenes estudiantes que durante el siglo XIX deciden abandonar su lugar de residencia para estudiar en París, sumándose a una larga lista de pianistas españoles y catalanes que deciden mejorar sus estudios de interpretación en la capital de Francia. La afluencia había comenzado, según Bergadà6, tras la restauración en el trono de Fernando VII, momento en que un número importante de artistas se refugian en el país vecino. Entre los pianistas en París de esta primera oleada se encuentra a Santiago de Masarnau o Pedro Pérez Albéniz, y ya más adelantado el siglo a Joaquín Malats o Ricardo Viñes, amigos íntimos del compositor.

No se conoce la fecha exacta de llegada del compositor a París. Según Granados en sus memorias ${ }^{7}$ habría llegado en 1885 , pero sus investigadores se inclinan por $1887^{8}$, aunque algunos sugieren 1888. Carol Hess ${ }^{9}$ y Walter Clark ${ }^{10}$, los dos investigadores de referencia en el estudio del compositor, se inclinan por 1887, fecha que ratificamos. Ambos se basan en el testimonio de Ricardo Viñes, amigo íntimo del compositor desde la estancia de ambos en París, tal como relata en el citado artículo de 1916 dedicado a Granados en la Revista Musical Hispano-Americana. Viñes relata con fechas concretas las peripecias de su amistad con el compositor, posiblemente basándose en los datos que él mismo tomó en su diario ${ }^{11}$.

${ }^{5}$ GUBISCH-VIÑES, Nina. Ricardo Viñes à travers son journal et sa correspondance (contribution à l'histoire des relations franco-espagnoles à l'aube du XXe siècle).Tesis doctoral en París 4. París, 1977,

${ }^{6}$ BERGADÀ, Montserrat. "Les pianistes espagnols au Conservatoire de Paris au XIXe siècle" Echanges musicaux franco-espagnols, XVIIe-XIXe siècles. Actes des Rencontres de Villecroze (15 au 17 octobre 1998) réunis par François Lesure. - Paris: Klincksieck, 2000. Pp. 195-233.

${ }^{7}$ VILA SAN-JUAN, P. Papeles íntimos de Enrique Granados. Barcelona: Amigos de Granados,1966.

8 Por ejemplo, Henri COLLET en Albéniz et Granados (París: Libr. Félix Alcan, 1925); Andrés RUIZ TARAZONA en Enrique Granados, el último romántico (Madrid: Real Musical, 1975) o Antonio IGLESIAS en Enrique Granados: (su obra para piano) (Madrid: Alpuerto, 1985-1986).

${ }^{9}$ HESS, Carol. Enrique Granados. A Bio-Bibliography. Nueva York: Greenwood Press, 1991.

${ }^{10}$ CLARK, Walter A. Enrique Granados. Poet of the piano. New York: Oxford University Press, 2006.

${ }^{11} \mathrm{El}$ entonces jovencísimo pianista comenzó este documento en el momento en que inició el viaje con sus padres hacia París el 12 de octubre de 1887. Este diario lo custodia actualmente Nina Gubisch, a partir del cual realizó su tesis doctoral ya citada, que desgraciadamente no se nos ha permitido consultar. Es por esta razón que las fechas que manejamos del diario de Viñes se han extraído del libro The Musical Kaleidoscope de Elayne BRODY, The Musical Kaleidoscope, 1870-1915. New York: Braziller, 1987. Elayne Brody aparentemente pudo consultarlo. 
Uno de los puntos controvertidos de su estancia estudiantil es su acceso al Conservatorio. Según el propio Granados, después de llegar a París unas fiebres le mantuvieron inconsciente unos 15 o 20 días en el Hospital y después estuvo algunas semanas convaleciente, por lo que no puso presentarse al examen de acceso, que tuvo lugar el 7 de noviembre:

"Lo primero que hice al llegar a París fue perderme y estar durante más de media hora dando vueltas al hotel "Cologne et d'Espagna" donde me había alojado (...) Una terrible enfermedad (...) a poco, muy poco, acaba con mi vida. Una tarde fui sacado en coche del hotel y conducido a la "Maison de la Santé". (...) Mi convalecencia duró más de tres meses durante los cuales perdí todo derecho a entrar en el Conservatorio, pues cumplí la edad reglamentaria y el plazo que se concedía para la admisión sin poder presentarme a las oposiciones"'12.

El relato de Viñes corrobora que Granados estaba convaleciente cuando llegó a la ciudad:

"hace veintiocho años y medio, cuando el pobre comenzaba a reponerse de una gravísima dolencia -un tifus maligno- que, apenas llegado de Barcelona, le tuvo algunas semanas entre la vida y la muerte (...) Tenía Enrique a la sazón veinte años y sólo doce contaba yo (...)”13.

Sin embargo, en la declaración de convalecencia de Granados hay una serie de contradicciones implícitas que no ayudan a esclarecer por qué no entró como alumno. Según acabamos de leer, Granados excedió la edad reglamentaria al cumplir años mientras estaba enfermo, pero la edad máxima de acceso al Conservatorio de París era de 22 años $^{14}$, y Granados tenía 20 cumplidos, tal como atestigua Viñes. Según Bergadà y Carol Hess, la razón fue que sólo se admitían dos alumnos extranjeros por clase ${ }^{15}$, y por esta razón Granados no fue aceptado, como tampoco lo fue Viñes por esta causa

\footnotetext{
12 VILA SAN-JUAN, P. Papeles intimos de Enrique Granados... op. cit., p.

13 Este párrafo del artículo de Viñes ya citado de la Revista Musical Hispano-Americana podría parecer un tanto vago en su afirmación "veintiocho años y medio". Sin embargo, parece completamente exacto con las fechas que maneja: siguiendo el diario, Viñes llegó a París el 13 de octubre de 1887 y el 17 de octubre se instalaba en el Hotel Cologne de la rue de Trévise exactamente 28 años y seis meses después de que Viñes escribiera sus recuerdos sobre la estancia de ambos. Aunque en el artículo se da como única referencia "primavera de 1916" podemos aventurar que fue escrito en abril, mes en que se conoció que Granados y su esposa habían fallecido.

${ }^{14}$ Cuando Granados pretende acceder al Conservatorio en 1887 éste se regía por los Règlements géneraux de 1878, el cual, en el Capítulo II (Des Éleves, de leur admission, de leur droits et de leurs devoirs) establece en el artículo 39 la edad máxima en 22 años.

15 Eso es una modificación que se incluyó definitivamente a los "Règlements géneraux" citados el 6 de agosto de 1894
} 
según su diario ${ }^{16}$. Gracias a la revisión de los documentos del Conservatorio sabemos que Granados no llegó a presentarse al examen de acceso ${ }^{17}$, probablemente porque ya estaban cubiertas las plazas para extranjeros y no por la enfermedad que menciona en sus memorias ${ }^{18}$.

Durante el curso 1888-1889 no hubo posibilidad de incorporarse a las clases del Conservatorio porque no se abrieron plazas para estudiantes de piano ese año ${ }^{19}$, aunque Granados estuvo preparando intensamente su examen de acceso en 1888, según apunta Bergadà $^{20}$.

Viñes y Granados asistieron como oyentes a las clases en el Conservatorio. Respecto a este aspecto guardamos pocas dudas gracias al testimonio de Viñes, aunque Granados no aparece tampoco en las listas oficiales de oyente. Según Ricardo Viñes, el profesor Charles de Bériot les daba clases en el Conservatorio, en la Academia Schaller ${ }^{21}$ y en su casa. Al año siguiente, y tras cumplir la edad límite para el acceso a las clases oficiales, Granados regresa a España.

En París no recibió una formación musical más allá de la interpretativa. Asistió a clases de armonía ${ }^{22}$ pero no se sabe con quién. Podría tratarse del mismo profesor que Viñes, Gaspard Villate, aunque es una mera especulación. Según Rafael Mitjana ${ }^{23}$, Granados estudió piano con De Bériot y composición con Jules Massenet, lo que no es

\footnotetext{
${ }^{16}$ BRODY: The Musical Kaleidoscope... op. cit., p. 170.

${ }^{17}$ En los Inventarios del Conservatorio de París (AJ/37) y en la lista de aspirantes revisada (AJ/37/329/2) Granados no aparece entre ellos. En Le Ménestrel del 13 de noviembre se publican los admitidos entre quienes se encuentra Édouart Risler, y en las clases preparatorias, Raoul Laparra y Alfred Cortot. Con los tres pianistas tendría más tarde una relación cercana, especialmente con Risler y Cortot.
}

${ }^{18}$ La enfermedad también se explica en la biografía de Granados que escribe Le Monde Musical el 30 de junio de 1914. Esta justificación de Granados prestaría una coartada a la sociedad francesa, dando una salida elegante a esta "falta de cortesía".

${ }^{19}$ Le Ménestrel anunció que presumiblemente el Conservatorio no abriría nuevas plazas, por lo que no se podría concursar de nuevo para entrar como alumno oficial. Este hecho se ve corroborado en la revisión de los Inventarios del Conservatorio (AJ/37/333/1) en que se certifica que no hay examen de admisión para alumnos activos de piano en 1888.

20 Bergadà se basa en un extracto de la memoria de musicología del Conservatorio Nacional de París (1971) que realizó Nina Gubisch-Viñes titulada Les années de jeunesse d'un pianiste espagnol en France (1887-1900). Journal et correspondance de Ricardo Viñes.

${ }^{21}$ El cours Schaller era una escuela privada. El 4 de noviembre de 1888 en Le Ménestrel se habla de la reapertura de las clases de diferentes escuelas y profesores, en los que se encuentran el cours Schaller (5, rue Geoffroy-Marie) donde De Bériot imparte clases de piano.

${ }^{22}$ VIÑES: “Enrique Granados...” Revista Musical Hispano-Americana, op. cit., p. 5.

${ }^{23}$ MITJANA, Rafael. "Pro Patria”. La Dinastía, 10 de julio de 1894. 
cierto. El 15 de noviembre de 1888 Ricardo Viñes señala en su diario que Granados tenía una cita con Massenet ("Esta mañana, Granados ha venido a vernos y dijo que iría luego a casa de Massenet") y sin embargo no se conocieron entonces, ya que según la carta de Massenet a Granados del 15 de julio de 1896 Massenet espera conocerle personalmente (“iSería tan feliz de conocer personalmente a un artista, a un maestro como Ud.!").

En el aula de De Bériot asistía a las mismas clases Ravel, y Gubisch se pregunta si el propio Granados pudo tener una relación de amistad con él. En el artículo de Revue Internacional de Musique Française, n², junio 1980 "Le journal inédit de Ricardo Viñes (Ravel, Debussy et Duparc)" Nina Gubisch señala que el jueves 11 de abril de 1889 Granados estaba con Viñes en casa de la madre de Ravel junto con Malats, entre otros. Aún así la relación entre ambos en los años de estudiante es mera conjetura.

Como es sabido, Granados residió el primer año en la Rue de Trèvise, calle muy cercana al Conservatorio, y al año siguiente, según Viñes, sufrió una "crisis de montmartrismo", trasladándose al barrio de Montmatre en la rue Fontaine, 48. El barrio estaba en pleno auge, y seguramente fue un movimiento cultural y social difícil de resistir para un joven de 20 años en un París lleno de atractivos.

Granados no sabía francés antes de ir a París tal como asegura él mismo en sus memorias, y éste es un punto interesante mencionado en la tesis de Gubisch, ya que, aunque el grupo español se iría ensanchando, se mantendría cerrado al mundo parisino. Este hecho, unido a que Granados tenía un carácter tímido e inseguro, ocasionaría que no aprovechara su residencia en París para hacer amistades francesas del mundo musical, aunque sí para ir a conciertos y oír a los grandes pianistas de la época que habían sido primeros premios en el Conservatorio ${ }^{24}$.

Respecto a los conciertos que Granados pudiera haber ofrecido en París en esa época, sólo queda el testimonio de Viñes porque no se encuentran referencias de los mismos con Granados como intérprete. El primero es una audición de alumnos del Conservatorio en la Salle Erard el 24 de mayo de 1888 donde ambos habrían tocado el Rondó en Do mayor de Chopin del que no se encuentran referencias, y el segundo no

\footnotetext{
24 Por ejemplo el martes 28 de febrero de 1888 Viñes y Granados fueron juntos al concierto de Monsieur Isidore Philipp (primer premio del conservatorio de París), que más adelante sería un admirador de su obra, tal como atestigua el epistolario. Incluso en una postal posiblemente fechada en 1912 Philipp afirma que incluyó el Allegro de concierto de Granados en un concierto suyo en Holanda.
} 
parece que tuviera lugar. Se trata de un concierto de Granados acompañando al virtuoso violinista húngaro Ernö Hubay (Budapest 1858-Viena 1937) el 4 de mayo de 1889, según Gubisch. En Le Menestrel del 12 de mayo, se señala que, con Hubay, tocaron Mme. De Serres y M. Jules Delsart, y no cita a Granados en ningún momento.

\section{Posibles viajes a París}

Desde su regreso en 1889 hasta 1905 hay indicios de viajes brevísimos del compositor a París, aunque son datos que no se han podido contrastar. Según la carta de Granados a Viñes del 15 de enero de 1894, el compositor habría estado en París seguramente a primeros de 1894 o a finales de 1893 para reunirse con De Bériot, sin encontrarle. Quizá pretendiera enseñarle personalmente sus últimos cuadernos de Danzas, ya que su maestro había juzgado uno de sus álbumes de Danzas en el verano de 1892. A juzgar por la epístola a Viñes, Granados tenía pensado volver a París en octubre de 1894, pero debió de cambiar sus planes ya que en septiembre se había trasladado a Madrid con el objetivo de aprobar las oposiciones a profesor de piano del Conservatorio.

Según el testimonio de Borrás de Palau $^{25}$, en 1898 Granados realizó un viaje a París en que estrenó una obra sinfónica llamada Desolació, aunque no se conservan manuscritos de esta obra ni hemos encontrado ninguna fuente hemerográfica o de cualquier otro tipo que corrobore este dato. Finalmente, según Joaquín Nin en "Evocaciones sobre Enrique Granados"26, en 1904 Granados fue a París y presentó al compositor francés Leon Moreau su obra lírica Follet. Granados conocía a este compositor por haber dirigido su orquesta Sociedad de Conciertos Clásicos el 4 de noviembre de 1900 en Barcelona, y en marzo de 1901 Granados dio un concierto con Moreau, también en Barcelona. Asimismo, éste interpretará algunas Danzas en París. Esta es toda la relación que se conoce entre ambos pianistas y compositores.

\footnotetext{
25 BORRÁS de PALAU, Joan. "Enrique Granados" La Ilustración Musical Hispano-Americana, junio 1 de 899.

26 NIN, Joaquín. "Evocaciones sobre Enrique Granados” Revista Musical Hispano-Americana, 31 de mayo de 1916.
} 


\section{La recepción de Granados como compositor-intérprete en la ciudad a través de sus conciertos, su obra y sus relaciones personales.}

Tal como ya se ha señalado, en las publicaciones musicales contemporáneas prácticamente no hay referencias a Granados hasta 1909. Únicamente algunos pianistas incorporan alguna obra de Granados en su repertorio pianístico, y siempre se reduce a las Danzas, su obra característica por antonomasia hasta que es sustituida por las Goyescas en el repertorio internacional.

Según Bergadà27 ${ }^{27}$ Joaquín Malats fue el primer pianista que tocó una Danza de Granados en un concierto público en París el 14 de febrero de 1896, aunque, tal como menciona Granados a Viñes en la carta que le escribe el 15 de enero de 1894, es muy posible que el pianista leridano interpretara en audiciones privadas algunas de sus obras, presumiblemente las Danzas. Viñes será el principal difusor de Granados, aunque el repertorio se limita únicamente a una selección de esta suite pianística hasta 1913.

En los festivales de música catalana de la Schola Cantorum de 1900 y 1905 también interpretaron algunas Danzas españolas ${ }^{28}$. El martes 11 de diciembre de 1900 en la Schola Cantorum se ofreció el primer concierto de música extranjera de la asociación, consagrado en esta ocasión a la música catalana; en esta ocasión Henri Duparc interpretó Granados y Albéniz. Viñes también interpretó las Danzas I, II, V y VI el 9 de enero de 1904 en la Sala Erard bajo los auspicios de la Societé Nacionale. León Moreau es otro introductor de las Danzas en París, ya que da un concierto con cuatro Danzas españolas en 1901, y Marie Panthès en 1906.

\footnotetext{
${ }^{27}$ BERGADÀ, Montserrat. Les pianistes catalans á Paris entre 1875 et 1925 contribution á l'étude des relations musicales entre la France et l'Espagne. Tesis doctoral. Tours, 1997. II parte: "Les pianistas catalans á Paris (1895-1925)". III "Les trois figures de proue : Capítulo 11 : «Enrique Granados » 2. «Diffusion de l'œuvre en France ».

28 En 1905 Blanche Selva interpretó los Cantos de España y Vega de Albéniz; Viñes interpretó dos Danzas de Granados y de Albéniz Torre Bermeja y la Sevillana; Marie Gay, "de voz siempre maravillosa", canta canciones populares y lieders de Joan Gay y de J. Civil. También participó Llobet, el guitarrista, al que dedican encendidos elogios ("intensidad y diversidad de sonoridades"; "Es simplemente prodigioso y emocionante al más alto grado, y deseamos vivamente que Llobet haga escuela, incluso en Francia"). Le Menestrel, 6 de mayo de 1905.
} 


\section{Concierto en la Sala Pleyel de 1905}

En 1905 Granados realiza el primer concierto confirmado en París en la sala Pleyel. Lo lleva a cabo junto al violinista belga Mathieu Crickboom ${ }^{29}$ el 31 de marzo. Granados interpretó seis Sonatas de Scarlatti transcritas por él mismo, y algunas obras de Chopin como solista (Nocturno en Do \# m, Polonesa $\mathrm{n}^{\mathrm{o}} 2$ y Balada $\mathrm{n}^{\mathrm{0}} 3$ ); con Crickboom interpretó la Follia, una sonata de Corelli y la Sonata de César Frank. En los bises Granados tocó dos obras propias. Según Le Monde Musicalº se trataría de un Estudio y una Danza española y, según Le Guide Musical ${ }^{31}$, dos Estudios.

Ricardo Viñes, en su diario, el 31 de marzo de 1905 afirma que "Granados ha tocado muy bien y ha tenido un gran éxito". En una carta de E. Risler a Granados de 1905 el pianista se muestra entusiasta: "Por fin un artista, después de tanto farandulero y de tantas nulidades. Hacía ya largo tiempo que yo no había experimentado tal impresión. Sus Scarlattis y Chopins quedarán inolvidables para mí"32.

La crítica de Le Monde Musical realizada por Jean Huré continúa en la misma línea:

"Enrique Granados, que es uno de los compositores más deliciosos que hayan jamás existido (...) se hizo oír, en la Sala Pleyel, como pianista. Él iguala incontestablemente a los más grandes por un virtuosismo audaz, elegante, siempre impecable, a veces endiablado....él sobrepasa casi todos los que he oído por su extraordinaria personalidad, y sin embargo siempre respetuosa hacia la obra interpretada.

Esta interpretación distinguida y encantadora concierne particularmente a Chopin. (...) Granados saca de su piano unas sonoridades variadas y pasa con una simplicidad increíble de los acentos enérgicos a las dulzuras más exquisitas. ${ }^{33}$.

\footnotetext{
29 Este violinista belga (Hodimont (Lieja) 1871-Bruselas, 1947) fue discípulo de Eugène Ysaÿe, de cuyo cuarteto fue segundo violín hasta 1894, cuando pasa a ser primer violín del Cuarteto de la Sociedad Nacional de París. Tras su viaje a Barcelona en otoño de 1895 se instala en la ciudad donde funda en 1897 la Sociedad Filarmónica, y, según el epistolario de Enrique Granados, forman la Academia de la Sociedad Filarmónica junto a Pablo Casals. Ese mismo año conforman un trío con el que hacen una gira por el Norte de España. A pesar de la escisión de Granados en 1900 para crear su propia Academia, ambos pudieron solventar sus diferencias y mantener una relación cuando menos profesional el resto de su vida.

${ }^{30}$ HURÉ, Jean. “Salles Pleyel. Concert Granados-Crickboom”. Le Monde Musical, 15 de abril de 1905. Parte del artículo está traducido en Enrique Granados.Algunas opiniones de la prensa... op. cit., pp. 4-5.

31 T. Le Guide Musical. 9 de abril de 1905

32 Luis VILLALBA: Enrique Granados. Semblanza y biografia. Madrid: Imprenta Helénica, 1916. La carta está publicada en la Revista Musical Catalana de 1905 "Una carta d'en Risler a n'en Granados" (p. 109) (CLARK: Enrique Granados... op.cit., p. 221).

Debe tratase de la carta en la Revista Musical Catalana de mayo de 1905.
}

${ }^{33}$ HURÉ, Jean. "Salles Pleyel....", op. cit. 
Le Guide Musical también hace hincapié en sus cualidades como intérprete español, aunque haciendo hincapié en que "hace honor a la escuela francesa" por haber sido alumno de De Bériot. También destaca su labor como intérprete de Chopin, el "poète du piano", sobrenombre que también se le da frecuentemente a Granados.

"Buscaremos en vano las cualidades que le faltan; las tiene todas: la fuerza y la delicadeza en la sonoridad, la rectitud de la medida, la firmeza y la anchura de estilo y el dominio de sí mismo que da seguridad a su interpretación y al auditorio (...). [Granados] supo desempeñar el nocturno el encanto que es posible obtener cuando no se recibió la transmisión directa del pensamiento de Chopin mismo"34.

Granados se presenta como intérprete ante el público francés, ya que, a pesar de que estrena las transcripciones de las Sonatas de Scarlatti en las cuales incorpora "floridos adornos típicos del romanticismo de finales del siglo XIX"35, las escasas críticas que recibe sólo se refieren a la parte interpretativa. Sólo las dos publicaciones mencionadas hacen eco del concierto, por lo que, pese a las buenas crítica y el éxito que menciona Viñes y que certifica el crítico de Le Guide, apenas tiene repercusión ${ }^{36}$.

\section{El año 1909, comienzo de su carrera internacional.}

El año en que se conoció y se despertó el interés por Granados fue 1909 a partir de los dos conciertos que dio con el violinista Jacques Thibaud a principios de junio en la Salle des Agriculteurs ${ }^{37}$. Previamente Granados había sido invitado por Fauré a formar parte del jurado en prestigioso Premio Diémer que tuvo lugar los primeros días

\footnotetext{
34 T. Le Guide Musical. op. cit..

35 HESS: Enrique Granados...op. cit., p. 24.

36 En Le Courrier Musical, por ejemplo, el 15 de marzo se anuncia el concierto Crickboom-Granados pero no hace mención a ellos en los números siguientes. Sí lo hace, en cambio, con Viñes, quien realiza su serie de cuatro conciertos de música para teclado desde la música antigua hasta los días de sus contemporáneos empezando el 27 de marzo hasta el 17 de abril. No aparece el programa de CrickboomGranados y tampoco hay una crítica del concierto.

37 En el concierto del 2 de junio se interpretó la Sonata $n^{\circ} 3$ en Mi M de Bach, Sonata en Do m de Beethoven y Sonata en Re m de Schumann; en el del 9 la Sonata en Si b M de Mozart, Sonata para violín y piano de César Frank y la Sonata Kreutzer de Beethoven.
} 
de mayo, donde se codeó con grandes pianistas contemporáneos ${ }^{38}$. En 1912 Granados sería invitado de nuevo como jurado del mismo concurso, que en este caso tuvo lugar el 1 y 2 de mayo. Además, en una fecha no determinada de 1910 fue nombrado jurado del claustro de Doctorado de Piano del Conservatorio de París ${ }^{39}$ junto a Dubois, Fauré, Paderewski, Planté, Pugno y Saint-Saëns. Por esta causa se le tributa a Granados un homenaje oficial que tuvo repercusión en toda España, desde el periódico gijonés $E l$ Noroeste a la Ilustración Artística.

Esta considerable actividad parisina se contradice con los hechos anteriores a 1909 y hace que nos preguntemos por qué un pianista desconocido internacionalmente es invitado a formar parte de un prestigioso premio por uno de los compositores y personajes musicales más influyentes de París, Gabriel Fauré. La respuesta que parece más evidente es que el compositor francés conociera personalmente a Granados en el viaje que realizó a Barcelona en marzo del mismo año para participar en los conciertos III y IV de Cuaresma y una Sesión íntima (11, 12 y 14 de marzo de 1909). Previamente tenían contacto gracias a Isaac Albéniz, amigo íntimo de ambos, ya que Granados iba a estrenar la Balada de Fauré en Barcelona ${ }^{40}$. Otra posibilidad más es que Granados había tomado contacto con Saint -Saëns a partir de su concierto conjunto en el "Festival Saint-Saëns" en abril de 1908 en Barcelona, y a continuación con Jacques Thibaud también en Barcelona el 8 de noviembre del mismo año. La concurrencia de los tres grandes músicos en Barcelona y la coincidencia con Granados pudieron motivar su

38 El jurado del premio Diémer estaba formado, además de Granados, por Fauré, Raoul Pugno, C. Chevillard, Rosenthal, Moszlowski, Leroux, Lavignac, Vidal, A. de Greef, H. Bauer, A. Pierret y Batalla. El 30 de abril de 1909 Le Monde Musical afirma: "Por tercera vez se va a disfrutar en París el 3 y 4 de mayo a las 9 de la mañana, en la sala del Conservatorio el concurso Diémer reservado, como se sabe, a los titulares de los primeros premios de piano del Conservatorio durante los diez últimos años". La segunda vez que fue invitado a participar en 1912 el jurado fue el siguiente: Gabriel Fauré, Lavignac, Chavillard, Risler, Moszkowski, Emil Sauer, Pierret, De Greef, Granados, Staven-Hagen, Lortat, y de nuevo Bourgeat como secretario.

39 Según Fernando Periquet en un artículo de 1910 sobre el Premio Diémer, "Poco después ingresó en el claustro del "Doctorado de piano", fundado por la "Sociedad de músicos de Francia" (PERIQUET, Fernando. "Granados, y el premio Diémer" El Imparcial. Madrid, 16 de diciembre de 1910). Según Juan Riera (RIERA, Juan. Enrique Granados (Estudio). Lleida: Instituto de Estudios Ilerdenses, 1967) fue nombrado Jurado permanente del Conservatorio de París. La única referencia que encontramos sobre este tema en el epistolario del compositor es la tarjeta que envía Granados a Joan Borrás de Palau, sin fecha, en la que Granados ha impreso: "Del comité de exámenes de París para la enseñanza del piano y Doctorado musical en Francia. Del Jurado del Conservatorio de París para el Gran Premio Diémer"

40 "En una palabra: yo tenía que tocar la Balada de Fauré; para mí una de las más altas honras de mi vida. Pues bien: por diferencias habidas con dicha sociedad, diferencias algo serias, mi dignidad no me ha permitido presentarme en público dependiendo de esos señores”. Carta de Enrique Granados a Isaac Albéniz. Barcelona, 15 de enero de 1909. 
invitación al año siguiente, primero como jurado y después como intérprete. Según Mangeot en Le Monde Musical del 15 de junio de 1909 « Enrique Granados »: "M. Granados no hubiera osado quizá jamás presentarse a un concierto si los mejores consejeros, y especialmente Saint-Saëns, no le hubieran empujado. Hoy su reputación se afirma como una de las más asentadas". Aunque Saint-Saëns había ido frecuentemente a España, no es hasta 1908 cuando conoce realmente al Granados intérprete y compositor. En 1909 Granados dedica a Saint-Saëns su concierto para piano que aparentemente iba a estrenar con la Asociación Musical de Barcelona pero que, por problemas con ésta, no se lleva a cabo ${ }^{41}$.

Este apoyo francés se debió en gran medida a que la sociedad musical espera que Granados retome el lugar que dejó en París Albéniz tras su muerte como compositor español. Mangeot en junio de 1909 da la clave: “¿Hablaremos del compositor? Es uno de los más interesantes de la joven España y hoy toma el lugar que se ha quedado vacío tras la muerte desastrosa de Albéniz"42. En portada Granados aparece al lado de Albéniz, quien acaba de morir. Debajo de Granados se lee "Pianista-compositor español que acaba de dar dos conciertos con Jacques Thibaud", y por primera vez aparece un repaso de la obra de Granados que va más allá de las Danzas españolas al mencionar gran parte de su producción:

“12 Danzas españolas, de un sabor exquisito; un Álbum de seis piezas: Preludio, Ecos de la parranda, etc...; un Álbum de la juventud, digno de ser comparado con el de Schumann; seis Estudios expresivos, fáciles; los Valses poéticos; un Allegro de concierto, coronado por el Conservatorio de Madrid y ejecutado en los exámenes de las clases de piano; las Escenas Románticas; Oriental y Jota, piezas de concierto. Los pianistas descubrirán en estas obras verdaderas joyas, que habrá que hacer conocer en París (...) He aquí las grandes obras: Una Sonata para piano y violín; un Concierto para piano y orquesta; cuatro obras dramáticas: María del Carmen (3 actos), Follet (2 actos); Petrarca (1 acto), Gaziel (1 acto); dos poemas sinfónicos: Dante (en dos partes) y Romeo y Julieta"43.

\footnotetext{
41 "Yo estaba escribiendo un concierto de piano y orquesta, el que debía yo mismo estrenar y como podrás suponer, me hacía una ilusión inmensa el presentarme en esa forma: pero en vista de la [charranada] (digámoslo así) que me hicieron, me disculpé de tomar parte en ningún concierto más de ellos (...)” Ibídem.

42 MANGEOT, André. "Enrique Granados”. Le Monde Musical. 15 de junio de 1909.

${ }^{43}$ MANGEOT: “Enrique Granados...”op. cit.
} 
La crítica musical del concierto con Thibaud de la misma publicación transcurre por los mismos derroteros. Después de alabar la interpretación de ambos, especialmente la de Granados, hace hincapié en su escuela francesa de piano:

“¡Cómo decir, en términos suficientes, la poderosa emoción creada por los dos maravillosos protagonistas! (...) Thibaud está habituado a los laureles y sin embargo, hay que decir que jamás su arte fue más grande, más puro ni más sublime. Granados es de la raza de los grandes músicos, de los maravillosos intérpretes, de los que produce los Albéniz, los Casals, los Malats y los Viñes. Habiendo, como los dos últimos, pasado por la escuela de De Bériot”44.

En el mismo artículo se presenta a Granados como músico, e insta a que se presente en el futuro como compositor: "Las colosales ovaciones (...) comprometerán a M. Granados a presentarse, la próxima vez, como compositor”.

Las críticas de los conciertos de la Salle des Agriculteurs, además de en Le Monde Musical encontraron eco en Le Courrier musical del 15 de junio de 1909, en Comoedia con referencias el 4, 7 y 11 de junio; y en Le Guide Musical del 27 de junio $^{45}$. Hubo unanimidad a la hora de elogiar la interpretación de ambos, y excepto esta última revista, las demás mentaron la "sorpresa" que supone encontrar la figura de Granados en el panorama parisino. De Stoecklin afirma: "Estoy encantado de constatar el enorme éxito conseguido por Granados puesto que no es de ningún modo banal ver que un pianista se presenta al público parisino con obras de música de cámara"46. En Comoedia se señala:

“M. Granados, en efecto, se ha creado rápidamente una notoriedad de buena ley. Este pianista, que, por mi parte, no había tenido aún la ocasión de apreciar, puede ser comparado con los más destacados. Su virtuosismo es grande y la calidad de su sonido, muy bonito. M. Granados es- según se ha dichogeneralmente conocido en España como compositor. Numerosas son las obras que ya ha escrito para su instrumento (...) $[\mathrm{y}]$ ha producido también obras dramáticas. (...) Se ve que la personalidad de Granados es extremadamente interesante. Esperamos que se haga conocer en París como compositor un día cercano" $"$.

\footnotetext{
${ }^{44}$ L.R. "MM. Jacques Thibaud et Granados". Le Monde Musical. 15 de junio de 1909.

${ }^{45}$ Curiosamente no aparece nada en el Bulletin Français de le SIM, la misma publicación que en 1914 le ensalzará como uno de los mejores compositores de todos los tiempos.

${ }^{46}$ DE STOECKLIN, Paul. "MM. Granados et Jacques Thibaud" Le Courrier Musical 15 de junio de 1909.

${ }^{47}$ L. V. “2º Séance Jacques Thibaud-Granados” Comoedia. 11 de junio de 1909.
} 
Según Bergadà, a Granados se le conocía como intérprete, pero tampoco parece del todo cierto a tenor de las críticas que acabamos de ver. Asimismo, en una carta de junio de 1909, J. Saint -Jean afirma: "Hasta ahora el Sr. Granados no era conocido en nuestra casa más que como compositor: todos los músicos franceses en efecto, conocen y gustan sus adorables piezas de piano, tan coloristas, tan originales, y tan pintorescas", evidentemente refiriéndose a las Danzas. Continúa:

"Pero no conocíamos más que por reputación su talento de pianista virtuoso. Hace algún tiempo, el Sr. Granados fue escogido por Gabriel Fauré para formar parte del jurado del premio Diémer, en compañía de los más ilustres maestros de piano; y esto había atraído hacia él la atención del París musical. El anuncio de sus conciertos con Jacques Thibaud terminó de provocar la curiosidad: Thibaud tiene la reputación de rodearse sólo de artistas dignos de él”.

Por tanto, el hecho de que Granados fuese invitado por Fauré para ser jurado y que tocase un concierto con Thibaud atrajo sobre él la atención de la sociedad musical.

En la carta de Saint-Jean se asegura que "todas las notabilidades musicales de París brillaban en la primera fila de los espectadores. La espera del público no fue decepcionada, el Sr. Granados no solamente confirmó, sino que incluso sobrepasó su gran reputación (...). Deseamos verlo de nuevo pronto entre nosotros".

Como vemos hay una atmósfera inmejorable que aguarda ansiosa la llegada de un nuevo compositor español que se pretende que sea Granados. Dejando un resabio estupendo como intérprete que destaca en una de las cualidades francesas por excelencia, el sonido ${ }^{48}$, remarcado por su ascendencia pianística francesa a través de sus estudios con De Bériot, queda el camino preparado para su presentación como compositor.

\section{Aceptación en la sociedad parisina como compositor: el concierto de 1911}

Según señala Alfonso Albéniz ${ }^{49}$, Granados se sintió transformado ante la muerte del compositor gerundense y decidió reorientar su vida profesional a partir de los últimos consejos del finado. Durante el mismo verano de 1909 Granados comienza a componer Goyescas, obra que presentará en la parisina Sala Pleyel el 1 de abril de 1911.

${ }^{48}$ Le Guide Musical destaca la calidad en sus "menores matices" y Stoeklin en Le Courrier... señala que Granados "es un admirable pianista que no golpea". Jean Huré, completamente extasiado por la interpretación de Granados en Le Monde Musical, menciona que Granados tiene un "color" de sonido que le es propio.

${ }^{49}$ ALBÉNIZ, Alfonso. Revista Musical Hispano-Americana. 30 de abril de 1916. 
Con las Goyescas confirmará su valía a nivel compositivo, y cumplirá con las expectativas puestas en él: Granados se afirma como el sustituto de Albéniz, el futuro musical de España. Este concierto supone su consagración y entrada definitiva en la sociedad parisina y en la historia musical.

El compositor se presenta con un programa únicamente basado en su obra, interpretando dos Danzas españolas, Valses Poéticos, Allegro de Concierto, Azulejos, una transcripción de una Sonata de Scarlatti y el primer cuaderno de Goyescas. Según Le Guide du Concert, el programa estaba pensado para presentar la obra de Granados al público francés desde sus comienzos, de manera que se viera su evolución, que culmina con las Goyescas.

Al concierto asistieron numerosos artistas, lo que se califica como algo "extraño" ("Raramente tantos artistas habían asistido a la Sala Pleyel, raramente el auditorio fue más vibrante, más entusiasta, verdaderamente transportado por el gran artista barcelonés"50). Parece que un gran número de artistas quieren apoyar el futuro éxito de Granados, y en su concierto las facciones musicales parisinas se unen y reciben con entusiasmo su música. Según Turina:

\footnotetext{
“Gran éxito, entusiasmo general, sala llena, coro de virtuosos (Cortot, Landowska, Lévy, Viñes, etc.) (...) Una de las suertes de este compositor es que todo el mundo musical lo toma tal como es, sin análisis y sin autopsias malintencionadas en sus obras. No ha oído, como Malats, los silbidos de un envidioso del poulailler, ni la crítica de partidos se ha ensañado con él como suele acontecer a un scholista o a un conservatorial. Granados se sienta al piano y empeza su "Danza española en mi menor". ¡Ved las caras del auditorio: ni un d'indysta está ceñudo, ni un debussysta afila las uñas, todos reflejan una gran satisfacción (...)
}

La crítica del concierto en Le Monde Musical, firmado por A. M. [André Mangeot] comienza de la siguiente manera: "La personalidad de Granados es grande desde dos puntos de vista: como pianista y como compositor" ${ }^{\prime 52}$. Goyescas se toma como "la obra de música de cámara más importante que España haya producido" 53 y

\footnotetext{
${ }^{50}$ A. M. "M. E. Granados”...op. cit.

51 TURINA, Joaquín. Joaquín Turina corresponsal en París y otros artículos de prensa. Escritos de un músico. Granada: Junta de Andalucía, 2002. P. 44.

${ }^{52}$ A. M. "M. E. Granados" Le Monde Musical, 15 de abril de 1911.

53 J. M. «Las Goyescas d’Enrique Granados » Le Monde Musical 30 de junio de 1912.
} 
"no hay duda de que puede ser el estilo moderno español" 54 . Comoedia considera que dentro de las obras de los jóvenes compositores españoles las Goyescas "merecen una mención especial por su originalidad y su inspiración"55.

El concierto fue apoyado por la crítica de gran parte de prensa especializada, lo que contribuyó evidentemente a la consecución del éxito. En una primera revisión a las publicaciones que se hicieron eco del concierto (Le Monde Musical, Le Guide Musical, Le Courrier Musical, Revue Musicale SIM, Le Guide du Concert y Comoedia) llaman la atención tres aspectos importantes que detallamos a continuación.

El primero, la insistencia en encontrar en Granados al sucesor de Albéniz, hecho que Bergadà ya había hecho notar en su tesis doctoral. El propio Turina lo menciona ("en Goyescas se ve la enorme influencia de Albéniz"56). Es un punto de vista que también fomenta Granados de forma consciente, ya que incluye la obra Azulejos comenzada por Albéniz y completada por Granados tras su fallecimiento a petición propia del malogrado compositor- en el repertorio del concierto ("[Granados] pasa con toda la razón por ser el continuador del añorado Albéniz"57. "Goyescas [es] una obra singularmente atractiva que podemos poner en paralelo con la Iberia de Albéniz" ${ }^{98}$. “Granados en las Goyescas hace recordar a Albéniz, pero aunque sea tan profundamente nacional como éste, Granados es menos brillante, (...) menos "popular" podría decirse. (...) Pero [Granados] es más elegante, más aristocrático (...) más fino y más sensible" $\left.{ }^{59}\right)$.

Las Goyescas son el centro de las críticas. Según Clark, una de las razones por las que la obra tuvo tan buena acogida fue la fascinación francesa por Goya que había empezado a comienzos del siglo XIX, y en nuestro estudio confirmamos que uno de los puntos significativos de la calurosa acogida es que las Goyescas satisfacen al público parisino porque ven en la obra el pintoresquismo que buscaban en un compositor español. El nacionalismo español es el segundo aspecto a destacar en la recepción de la

\footnotetext{
${ }^{54}$ GUERILLOT, F. Revue musical mensuelle SIM. 15 de abril de 1911. P. 89

${ }^{55}$ Enrique Granados. Algunas opiniones de prensa...op. cit., pp. 7 y 8.

56 TURINA: Joaquín Turina. Corresponsal... op. cit., p. 44

${ }^{57}$ Ch. C. Le Guide Musical. 9 de abril de 1911. P. 287.

58 J. M. « Las Goyescas d’Enrique Granados » Le Monde Musical 30 de junio de 1912.

${ }^{59}$ J. M: « Las Goyescas d'Enrique Granados ...» op. cit.
} 
obra de Granados. La ligazón directa con Albéniz es una prueba, aunque la crítica francesa encuentra una música española con características diferentes a las del compositor gerundense. Según Ch. C., en las Goyescas dominan el ritmo y los acentos locales y están marcados por una fantasía delicada y de un sentimentalismo expresivo. J. M. considera que las Goyescas son el resultado de la evolución técnica en el tiempo del compositor, pero la esencia pintoresca de las primeras obras, es decir, las Danzas, se mantiene al estar construida sobre temas populares, aunque las Danzas están desprovistas de todo ornamento y las Goyescas tienen una escritura “polifónica, sólida, recia, (...) coloreado de preciosas armonías, muy modulante y muy tonal al mismo tiempo (...) y admirablemente pianístico"60. Incluso Federico Lliurat en "Barcelona" La Revue Musicale SIM de julio de 1911, repite el mismo comentario al mencionar el estreno de Goyescas y Cant de les estrelles. Según Lliurat la receta para la composición de las Goyescas es el color nacional unido al lirismo y el todo coloreado, poético, pianístico.

El tercer punto común a la crítica es la forma "narrativa" de las Goyescas. Todas las publicaciones, a excepción de la Revue Musicale SIM, hacen la misma descripción, lo que confirma que estas indicaciones fueron facilitadas por el propio compositor. Las Goyescas quieren ser una suerte de pintura de la vida española en la época de Carlos IV y

"evocan el amor entre dos majos: el majo siguiendo a la maja a través de las calles estrechas de Madrid murmura: Los Requiebros, los mil cumplidos discretos, delicados, compases que llenas de contento a la que se dirigen. A continuación sigue el dúo de amor Coloquio en la reja, amor doloroso, grande de presentimientos nefastos. Y, en efecto, siguen las quejas de la Maja abandonada a quien responde el Ruiseñor cuando cae la noche calma y misteriosa. El fandango termina esta primera parte"61.

Le Guide du Concert además anticipa el argumento de la segunda parte de Goyescas que no se incluye en el programa: "En la segunda el Majo muere después de una fiesta y aprendemos en un epílogo que su espíritu vuelve para darle una serenata a la Maja abandonada". Recordemos que el segundo cuaderno de Goyescas se compone de dos obras, El amor y la muerte, y la Serenata del espectro.

\footnotetext{
${ }^{60}$ Ibídem.

61 “Oeuvre de M. Granados”. Le Guide du Concert. 1 de abril de 1911.
} 
Como consecuencia del interés que suscita el compositor, ese mismo año dos publicaciones musicales, Le Guide Musical y Le Monde Musical hacen referencia a la obra lírico-teatral Liliana, estrenada en Barcelona en septiembre de 1911. Le Monde Musical incluso le dedica un artículo detallado escrito a partir de las propias indicaciones de Granados y con los mismos ejemplos musicales ${ }^{62}$.

Granados dejó París precipitadamente tras su concierto de $1911^{63}$. La carta de Wanda Landowska lo confirma, al tiempo que muestra el inusitado interés que levantó Granados:

“iUsted se nos fue tan precipitadamente! Estábamos muy inquietos por esta causa. Todos nuestros amigos se han entusiasmado por su arte y por usted. He aquí dos cartas que acabo de recibir: El Sr. y la Sra. Pollet, que a menudo dan grandes sesiones musicales en su casa, le invitan a cenar para el Domingo. El Conde Béranger de Miramon querría que tocase en casa de sus suegros, que pagan muy bien a los artistas. ¿Tiene la intención de volver a París? Y sobre todo ténganos al corriente de su salud, que es muy querida para nosotros."

\section{Incorporación inmediata de las Goyescas al repertorio pianístico internacional}

Según explica en una carta escrita el 7 de abril de 1911 en catalán un personaje sin identificar ${ }^{64}$, las críticas son fieles a la repercusión que tuvo su concierto: "Todo el mundo habla no más que de ti. Todos esperan el verano para empezar a trabajar tus obras. Veremos quién es el primero que las hace oír”. Según parece, Cortot es el más afectado por sus obras. El propio Thibaud se lo repite en otra carta del 5 de mayo de 1911 (“¡Usted tuvo en París un espléndido éxito desde todos los puntos de vista! Toda la gente que conozco que estaba allí ha estado entusiasmada, ¡Cortot está loco por usted!").

\footnotetext{
62 En la carta de André Mangeot a Granados del 3 de octubre de 1911, Mangeot pide información al compositor sobre Liliana. En la Pierpont Morgan Library de Nueva York se conserva la respuesta. Es una contestación de Granados a Mangeot con fecha del 22 de octubre de 1911 en la que Granados hace una descripción detallada de la misma que se transcribe casi literalmente en un artículo de Le Monde Musical "Siliana" [sic] de Granados á Barcelona" del 15 de noviembre de 1911. En él, Paul Martineau transcribe casi todos los ejemplos musicales que aporta Granados excepto los breves fragmentos sobre el que se canta: "per qu'ils aucells refilan", fragmento sobre « per qui les flors esclatan » y sobre « mes enllá de la selva, mes enllá ».

${ }^{63}$ Según la carta del entonces joven pianista José Iturbi a López-Chavarri del 5 de abril de 1911, lo hizo porque se encontraba enfermo, epístola transcrita con el número [262] en DÍAZ GÓMEZ, RAFAEL, GALBIS LÓPEZ, Vicente. Eduardo López-Chavarri Marco.Correspondencia. Edición Generalitat Valenciana, Valencia. 1996.

${ }^{64}$ Creemos que pueda tratarse de Lluís Millet.
} 
Alfred Cortot, dedicatario de la Serenata del espectro, fue uno de los primeros pianistas que interpretaron las Goyescas en París después del propio Granados. Según Bergadà, sólo Cortot y Montoriol Tarrés presentaron en París las Goyescas, pero el epistolario certifica que muchos de los pianistas contemporáneos más importantes del momento incluyeron inmediatamente después de este concierto Goyescas en su repertorio a lo largo del mundo, no sólo en Francia, sino en el resto Europa, EEUU y Rusia. Empezaron a hacerlo en 1912, año en que las Goyescas se publican. Además, Granados a partir de 1911 comienza a mantener un contacto regular con intérpretes de prestigio internacional que comienzan a estudiar e interpretar esta obra.

Harold Bauer es otro de los pianistas que estudia las Goyescas y que las toca en concierto, pero las critica e incluso las "recorta". Las cartas que se conservan en este epistolario dan testimonio de que Bauer pide permiso a Granados para hacerlo y que éste se lo concede ${ }^{65}$. Granados le dedica El amor y la muerte de Goyescas. Le había dedicado también su Rapsodia aragonesa. En la carta de Bauer a Granados del 12 de abril de 1913 Bauer muestra su agradecimiento y le anuncia que toca las Goyescas en sus conciertos: "Sé con gran placer que usted me dedicó el epílogo de sus bellas Goyescas. ¡Supongo que es El Amor y la Muerte del que hablamos hace tiempo y lo espero con impaciencia! Toqué mucho el Fandango y el Ruiseñor el último invierno y todavía [cuento con] tocarlos en América la temporada próxima”.

Édouard Risler, a quien dedica Coloquio en la reja, escribe a Granados el 22 de abril de 1912 certificando que incluye las Goyescas en su repertorio de concierto: "Lee $V d$. el programma ci-joint. Le tocare el año próximo en París, Jebe, Laussane, Lyon, Bordeaux y Madrid (Soc. Filarm.). Vd. vee que el progr. Comprende las Goyescas (complètes) de $V d$, que esta una obra que me gusta mucho'[sic]. La relación de Granados con este pianista es anterior a 1912, tal como atestiguan otras cartas del epistolario. Además en 1906 participaron juntos en dos conciertos a dos pianos en Barcelona, y en 1907 uno de los esponsors del concierto de Risler sobre las sonatas de

\footnotetext{
${ }^{65}$ Carta de Harold Bauer a Granados escrita desde Suiza el 1 de julio de 1912: "[D]esde hace quince días trabajo sus Goyescas, que encuentro exquisitas, y querría poder añadirlas a mi repertorio para tocarlas mucho y por todas partes. Pero (...) yo los encuentro demasiado largos (hablo de tres primeros solamente, el cuarto es una joya perfecta) y le pregunto si no hay medio de hacer cortes. Desde luego, jamás me permitiré aportar el menor cambio sin su autorización y su entera aprobación".
} 
Beethoven fue la Academia Granados, y este gran pianista formó parte del jurado del concurso de piano que organizó la Academia en 1911.

Arthur Rubenstein también interpretó las Goyescas poco después de publicarse. En dos cartas de Pablo Casals a Granados de los años 1913 y 1914 se menciona que este gran pianista polaco incorpora las Goyescas en sus conciertos ${ }^{66}$. El pianista francés Francis Planté no interpreta las Goyescas en concierto porque entre 1900 y 1915 está retirado de la vida pública, pero las aplaude:

"Querido y eminente amigo.

Acabo de recibir la visita de nuestro amigo M. Moullé, y para hacerle honor y celebrar musicalmente su presencia, he creído que no podía hacer nada mejor que hacerle oír Los requiebros y el Fandago del candil de su maravillosa colección Goyescas. (...) Su color, su acento, vibrante, y su aspecto elegante, seductor, lánguido si se da el caso (...)” Mont de Marsan, 27 de marzo de 1913.

Este mismo Édouard Moullé que se cita en la carta de Planté había mostrado su inclinación a favor de las Goyescas "contra" la Iberia de Albéniz. En la carta escrita al compositor desde París el 18 de julio de 1912 se muestra a favor del compositor leridano ("Oímos las grabaciones de Albéniz, le aviso que su música no me fascinó mucho, y tampoco a los oyentes que estaban presentes en la audición que no fue sensacional. Y sin embargo se tocó la Iberia. Hay mucha afectación en esta obra. Fue una desilusión para todos. Preferimos sus Goyescas, y mucho").

\section{El concierto en la SMI de 1914}

Entre los pianistas que incorporan Goyescas en su repertorio, Enrique Montoriol Tarrés jugará un papel importante sobre la recepción de Granados en París. El 3 de mayo de 1913 este pianista interpreta La maja y el ruiseñor y Requiebros en la sala de la Sociedad de Conciertos (Antiguo Conservatorio) en París, concierto del que se hacen eco Le Courrier Musical, Le Guide du Concert y Le Guide Musical.

El 1 de noviembre de 1913 Montoriol escribe un artículo para La Revue Musicale SIM “Á Barcelona: Une visite à Granados”, que presenta al compositor en su casa, destacando la austeridad de su vida y poniéndola en contraste con la importancia

\footnotetext{
66 Artur Rubenstein (Lodz 1887- Ginebra 1982). Pianista polaco, más tarde nacionalizado americano. Debutó en Londres con Casals en 1912 en el Queen's Hall. Fue un entusiasta de la música de Granados, Falla, Albéniz y Villa-Lobos. Como podemos ver, toca Goyescas en Rusia en 1913 y en París en 1914. En 1916, el día antes de que se conociera la noticia de la muerte de Granados en Barcelona este pianista había interpretado en el Palau de la Música La maja y el ruiseñor según Antonio Fernández-Cid en Granados (Madrid: Samarán ediciones, 1956), p. 35.
} 
de su obra. En 1914, poco antes del concierto de Granados en París, Montoriol Tarrés toca las Goyescas en la Salle Erard en la última quincena de marzo. En el concierto, según La Revue Musicale, Montoriol explica el argumento subyacente a la obra, seguramente preparando al auditorio para el concierto de Granados. Pocos días más tarde, Granados concede una entrevista antes del concierto, a la que acude con Montoriol Tarrés como introductor. La presentación del concierto la relatará extensamente Jacques Pillois en la Revue Musicale SIM (“Un entretien avec Granados”) el 15 de abril de 1914.

Montoriol Tarrés es uno de los artífices de la presentación de la ópera sobre Goyescas al director de la Ópera M. Rouché en su primera visita en 1914. En la carta a su mujer del 5 de abril Granados afirma: "Mañana me reúno en casa Montoriol con el director de la ópera para hacerle oír lo que tengo hecho de los Majos. Hay una atmósfera magnífica a favor".

Según el propio Montoriol ${ }^{67}$ Granados le envió sus Goyescas a París en 1913. Asombrado por la calidad de la obra, se puso en contacto con Émile Vuillermoz, redactor jefe de la Revue Musicale SIM para que hiciese reconocer la valía de la obra en París. Hasta esa fecha Montoriol Tarrés se confiesa un desconocedor de la música de Granados.

Si fue de esta manera en que se dio impulso al concierto, esto no significa que Vuillermoz no conociera ya la obra de Granados. A partir de una petición directa de la revista de la SIM (Societé Internationale de la Musicologie) a Granados, Vuillermoz se hizo con la partitura en 1911, y, por extensión, la Societé Musicale Indépendante (SMI), sociedad de la que Vuillermoz también formaba parte, y bajo cuyos auspicios Granados toca por última vez en París. En el epistolario familiar se conserva la carta de la Revue Musicale SIM con fecha del 30 de octubre de 1911 en la que se le solicita a Granados una copia de Goyescas para hacer referencia a la obra en su revista.

Desgraciadamente apenas sabemos nada del pianista catalán Enrique Montoriol Tarrés. En Le Monde Musical del 30 de marzo de 1898 aparece una reseña de su primer concierto en París en marzo de 1898. Por el artículo de Nin "Evocaciones" sabemos que era esposo de la pintora francesa Isabel Beaubois de Montoriol y por la Revista Musical

${ }^{67}$ MONTORIOL TARRÉS, Enrique. "Enric Granados”. Revista Musical Catalana, 1916. P. 195 
Catalana de abril de 1915 conocemos su traslado a Barcelona a consecuencia de la Gran Guerra (p. 116). Ambos estuvieron en casa de Nin en París en una reunión musical con Falla y Granados en abril de 1914 donde Granados interpretó parte de su ópera, y Falla su recién estrenada La Vie Bréve. Bergadà escribe una pequeña voz sobre este pianista en el Diccionario de la música española e hipanoamericana en que no explica cuáles eran sus relaciones o inclinaciones artísticas en París, pero por esta anécdota podemos intuir que Montoriol era más cercano a la facción innovadora que se organizó a partir de 1910 de la que la SIM y la SMI formaban parte.

Vuillermoz, redactor jefe de la Revue Musicale SIM, toma las riendas del concierto de Granados, también porque en ese momento a la SMI le era favorable. Las críticas que recibe en que, de alguna forma, se compara a Granados con Strawinsky que estaba en ese momento en París presentando Le Sacre du Printemps-, las realiza el propio Vuillemoz en las publicaciones Comoedia y Musica, ni siquiera en su propia revista. Por esta razón no parece extraño que una persona -a quien no hemos logrado identificar- de la Revue Musicale SIM le pida a Granados que reconozca públicamente el apoyo del redactor de dicha revista francesa en la carta escrita el 1 de julio de 1914. En ella incluso se sugiere que Granados recibe la Legión de Honor francesa en parte gracias a Vuillermoz ${ }^{68}$.

En el concierto del 4 de abril de 1914 Granados toca bajo los auspicios de la Societé Musicale Indépendante (SMI), sociedad escindida de la Societé Nationale (SN). La SMI acoge a Granados y le invita a participar en un concierto de presentación de la segunda parte de Goyescas. Le Monde Musical con André Mangeot al frente, que hasta entonces parece que fue el máximo impulsor de Granados en París, se queda en un segundo plano, aunque la crítica al concierto de 1914 es muy favorable, siguiendo la misma línea que las críticas y artículos de años anteriores.

El ambiente de la música seria parisina se había dividido desde 1909 en dos facciones, los conservadores y los innovadores. La causa fue la escisión de la Societé Nationale en 1909 y la inmediata fundación de la Societé Musicale Indépendante. La

\footnotetext{
68 "Es usted condecorado, es recibido en la Ópera, todo esto, gracias a la agitación que hicimos alrededor de usted y al trabajo que se tomó nuestro buen Vuillermoz. Sé que le sería muy agradable si pudiera ser recompensado por sus penas, es decir, si usted pudiera escribirle una pequeña palabra que él se apresurara a publicar en nuestro S.I.M., (...) Vuillermoz es extremadamente discreto y sé que jamás pediría la menor cosa, es por eso que su Director se pone en su sitio". París, 1 de julio de 1914.
} 
facción conservadora representada en la SN estaba capitaneada por Vincent d'Indy, fundador de la Schola Cantorum en 1896, que había convertido la Societé Nationale en una "sucursal" de su escuela. Esto era criticado por las nuevas generaciones de compositores, especialmente por Ravel, quien censuraba el bloqueo sistemático a la audición de obras que se alejaban de las técnicas compositivas de la Schola. Como resultado de las disensiones internas, Ravel dimite en 1909 y se funda la SMI. La SN y la SMI cohabitarán desde 1910 hasta 1935, al desaparecer la SMI ${ }^{69}$.

D’Indy era un ardiente defensor de la música francesa pero ligado a la tradición musical germana del siglo XIX y al formalismo. Según Duchesneau "es innegable que la importancia primordial se refiere a las formas tradicionales y a las técnicas de composición heredadas del siglo XIX"70.

El comité fundador de la SIM había sido conformado por L. Aubert, André Chalet, Roger-Ducasse, J. Huré, Koechlin, Ravel, Schmitt y Vuillermoz, quien jugó, como acabamos de ver, un papel primordial en la recepción del último concierto de Granados en París. El secretario fue Mathot y el presidente Fauré, quien no volvió a las reuniones pero sí dio apoyo público a la institución en su movimiento de rebelión que parecía justificado. Debussy se mantiene al margen, pero gracias a la intervención de Fauré también dará obras para estrenar en la institución. Entre 1910 y 1914 se dieron principalmente estas diferencias entre ambas sociedades $\mathrm{y}$, aunque había algunos compositores que se tocaban en las dos sociedades, eran los menos.

El concierto de Granados encajaría en una programación donde predominaba la música de cámara por la insuficiencia de medios financieros, donde destaca la música para instrumento solista (piano), cuartetos, quintetos, así como mèlodies para voz y piano. La estética de la SMI se basa en una "nueva tradición musical" fundada por Chabrier, Fauré y Debussy, en que las bases son nuevas inspiraciones temáticas y formales y de una armonía renovada. Utilizan sobre todo dos fuentes de renovación:

\footnotetext{
69 La SN tendrá una programación regular, lo que hace que tenga un impacto sobre el medio musical. Entre 1914 y 1917 las actividades de ambas sociedades se paran, pero las demás instituciones musicales parisinas también, a consecuencia de la guerra.

70 DUCHESNEAU, Michel. L'avant-garde musicale et ses sociétés à Paris de 1871 à 1939. Sprimont (France): Pierre Mardaga, 1997. P. 36
} 
exotismo y folclore. El exotismo viene de España, de oriente, de la música francesa antigua, del folclore y del jazz ${ }^{71}$.

Estas bases ideológicas de la SMI favorecieron que se realizara el concierto de Granados. En primer lugar, en la SMI se permitía acoger composiciones de compositores extranjeros - no era tan sencillo en la Societé Nationale dado que no se solía programar más que extraoficialmente- y en segundo lugar, la SMI impulsaba, por así decirlo, la obra extranjera que no se sometiera a parámetros clásicos. Así, la nueva sociedad permitió hacer conocer en Francia obras del extranjero que se juzgasen importantes por la mutación del lenguaje, de género o de forma que presentasen. Granados cumplía estas condiciones en la medida en que se trata de un compositor español que escribe una obra nacionalista española, y que utiliza una estructura musical no convencional en una obra camerística.

Según Duchesneau, la obra de compositores extranjeros y especialmente Granados, "abre una vía a una nueva música francesa que debe una buena parte de la eclosión de su sensibilidad musical a las influencias exteriores"72. Considera que Granados, con su abandono de formas estructurales preestablecidas -el autor está pensando en Goyescas, inevitablemente- influyó también en los compositores franceses, nombrándolo junto a Schoenberg, Kodály o Casella en la influencia que tuvo en Francia además de contribuir al ambiente "españolista" de las obras francesas. Seguramente estas afirmaciones son exageradas y sería necesario contrastar convenientemente esta opinión, aunque evidentemente sí contribuyó a la expansión del españolismo en París, especialmente en el repertorio pianístico y por supuesto Granados fue "adoptado" por la SMI para mostrar las posibilidades de expansión del lenguaje musical.

Por estas cuestiones podemos deducir que el público que recibió la segunda parte de Goyescas era distinto que al acogió a Granados tres años antes. Aunque hubo representantes de la música francesa del cambio de siglo, por lo que probablemente se recibió a Granados una vez más sin escisiones, en el concierto predominó “un gran

\footnotetext{
${ }^{71}$ El folclore francés regional también lo usaba la SN, pero no el resto.

72 DUCHESNEAU: L'avant-garde musicale... op. cit., p. 155.
} 
número de jóvenes notabilidades musicales"73. Según el propio Granados en una carta a su esposa Amparo Gal,

"El Embajador de España estuvo durante todo mi concierto, aplaudiéndolo entusiasmado. La Sala llena. Todo París de grandes hombres, allí. Strawinski [sic] [i], Smith, Huré, Casella, Lazare-Levy, Ecorcheville, Vuillermoz, y tantos y tantos que no sé ahora.

Ayer al acabar el concierto me acompañaron al café más de 60 artistas que estuvieron conmigo hasta las dos". París, 5 de abril de 1914.

La recepción del concierto del "Festival Granados" no pudo ser mejor. Tuvo lugar en la Sala Pleyel, y en él Granados presentó del segundo libro de Goyescas, dos Danzas españolas, la Serenata para dos violines y piano (con Costa y Zighera) y las Tonadillas con Mm. Polack como intérprete. Le Monde Musical, la única crítica consultada no dependiente de la SIM o SMI, presenta a Granados como un "reputado" compositor. Es decir, según esta publicación Granados se reafirma en su cualidad de compositor español. Le Monde insiste en su comparación con la Iberia de Albéniz, aunque, matiza, sin parecido entre ambas. En la crítica sobre las Tonadillas donde "rejuvenece la antigua canción española" se afirma que Mme. Polack se vio obligada a repetir las Currutacas modestas, aunque según Granados en la misma carta "Las Tonadillas a pesar de ser cantadas con desgracia gustaron mucho; sobre todo las Dolorosas y las Currutacas que se repitieron, luego tuve que tocar dos obras más fuera de programa teniendo que salir a saludar diez o doce veces. Más éxito que nunca".

En el suplemento de la Revue Musicale SIM Pillois condiera las tonadillas originales como "una fuente fresca e inagotable, sobre el que se concibe que él [Granados] tenga orgullo". En esta charla de presentación de su concierto Granados interpreta algunas, canturreando, pero dando la expresión que merece cada una: lánguida o vehemente, apasionada o nostálgica. El piano suena como una "guitarra lejana o canta como rozado por un invisible arco" y Pillois compara estas piezas con la sencillez de los lieder de Schubert. Estas canciones son“de una línea melódica (...) ideal" con "apoyos armónicos voluntariamente exentos de todo exceso, es realmente sorprendente". Le recuerda a "Schubert y tan alto como éste" aunque lo compara con la Vida de una mujer y El amor de un poeta de Schumann.

${ }^{73}$ A. G. "Festival Granados". Le Monde Musical. 15 de abril de 1914 
Otra cuestión interesante en la descripción de esta entrevista es lo que Pillois define como "punto sensible", el momento en que se trata del ritmo, ya que, según Granados, más que la melodía la diferenciación regional se basa en las diferencias rítmicas. Pone ejemplos al piano, de manera que utiliza de una danza bretona que en valores aumentados se concierte en un villancico de Navidad catalán.

Granados vuelve a París en junio de 1914 para recibir la condecoración de la Legión de Honor y tener la última entrevista con M. Rouché el 15 de junio donde se concretará el estreno de Goyescas en la Ópera de París.

El 16 de junio Granados escribe a su familia, explicando que es gracias al pianista norteamericano Ernest Schelling por quien ha conseguido finalmente que se admitan las Goyescas en la Opéra, y además otro posible estreno en Boston, aunque no se vuelve a saber nada acerca de esta última posibilidad.

\section{EI pensamiento noventaiochista en las Goyescas}

En la entrevista relatada por Pillois, Granados insiste en una concepción musical de una España diferenciada, que no hostil, haciendo una metáfora con los vientos que recorren la península. Parece que, según Granados, las corrientes pasan por toda España, tanto las septentrionales como las meridionales o africanas. Montoriol completa la disquisición del compositor explicando tres corrientes musicales en España: la norteña (Asturias, Galicia, Cataluña), la hispano-árabe (Murcia, Valencia, Andalucía) y la más pura que no ha sido "mancillada" por ninguna mezcla, la realmente ibera, la castellana, que es la que toma Granados para expresarse. Esta idea está claramente vinculada a la generación del 98. En el mismo artículo Pillois señalará que Castilla es lo que a Francia la Île de France: una lengua pura, sin mezclas.

Esta visión sobre España y su música se repite en todas las revistas musicales francesas. Esto nos hace plantearnos si es posible que Granados creyera que Castilla es el único lugar de España donde se puede encontrar "pureza" en los cantos. La cuestión se complica si pensamos que las Tonadillas no están basadas cantos populares en sí, sino en tonadilla española, lo que su maestro Felipe Pedrell llama folklorismo accidental. En cualquier caso, no hay contradicción entre la aplicación de las teorías pedrellianas con la supuesta pureza castellana descrita. Vuillermoz en la revista Musica en mayo de 1914 afirma: 
"Enrique Granados representa en su país el ser de la raza pura, el creador que inspira el alma de un pueblo. (...) La música española no es siempre una herencia sin mezcla. Sin hablar de los aluviones europeos de todo tipo que recubrieron la tierra vasca y catalana (...) es cierto que los dominantes del arte de Andalucía, de Murcia y de Valencia -el único, en el fondo, que sea artículo de exportación y en el que el color nos es familiar- donde origen extranjero y provienen de la herencia árabe y morisca recogida por las provincias. Solas, las voces de Castilla y de Aragón nos hacen oír el auténtico canto ibérico".

Vuillermoz repite la idea el 6 de abril de 1914 en Comoedia, dedicando el artículo también a Strawinsky. Según Vuillermoz, Strawinsky y Granados son representativos de la tierra originaria de cada uno y destaca la osadía del lenguaje de ambos, a pesar de las diferencias evidentes entre ellos. En Granados se señala, como siempre, la sensibilidad de su obra.

\section{El "moderno" estilo de Granados}

En general el moderno estilo español mostrado en Goyescas y Tonadillas gustó a la sociedad musical francesa. En los dos casos Granados abre una línea historicista en la composición en lo que se ha llamado "nuevo casticismo". Asimismo, se incorpora al importante movimiento instrumental y vocal internacional -es decir, alejado del género operístico- al componer una obra para piano y canciones de concierto en oposición a la canción de salón.

En general se ha venido repitiendo que la falta de forma en la producción de Granados es uno de las características débiles de la misma. Así, ya Turina en la crítica al concierto de abril de 1911 en la Revista Musical de Bilbao comenta a propósito de las Goyescas su "ausencia de construcción y de trabajo temático, modulaciones escasas y por lo tanto alguna monotonía"74. Sin embargo debemos tener en cuenta que la formación scholista de Turina, basada en la observancia de la forma, influyó negativamente a la hora de la valoración de Goyescas. Esta misma opinión también la repite el francés Henri Collet en su monográfico sobre Albéniz y Granados, y, siendo éste una de las referencias más importantes para los posteriores biógrafos españoles que, en su mayoría, no estudiaron la obra de Granados sobre partitura, o bien tenían una formación musical escasa, se acogieron esta opinión del francés repitiéndola de forma que se convirtió en un lugar común a la hora de valorar su obra en general.

${ }^{74}$ TURINA: Joaquín Turina. Corresponsal... op. cit., p. 45. 
Muy al contrario, como acabamos de ver, la falta de forma convencional es considerado por los integrantes de la SMI un valor positivo. Sin embargo no sería ésta la lectura que predominaría en la historiografía. Clark, prácticamente el primer biógrafo que se acerca neutral y detenidamente a la partitura de Goyescas, considera que la repetición de los temas en esta obra no proviene de una carencia de técnicas compositivas sino de las necesidades expresivas de la propia obra ${ }^{75}$.

Otro de los puntos interesantes es que el compositor descubre a los franceses "una nueva España"76, alejada por completo de los parámetros a los que hasta entonces estaban acostumbrados los franceses: presenta la historia musical española reescrita en un lenguaje en el que el elemento arábigo no es lo predominante, como lo había ocurrido hasta Albéniz. También Le Guide Musical el 12 de abril de 1914 menciona este aspecto al señalar que su lenguaje musical está alejado de "panderetas y tambores".

\section{Conclusión}

No es éste el lugar en el que se estudiará qué causas histórico-musicales hicieron que en 1905 la soberbia actuación de Granados pasara sin pena ni gloria, y sin embargo la de 1909 sea esperada con emoción y se vuelquen en ella esperanzas sobre la música española en París. Sería necesario hacer otro tipo de estudio. Sin embargo podemos concretar algunos aspectos que, a la luz de la revisión biográfica realizada, aclaran puntos sobre esta cuestión. Su brillante intervención de 1905 no tuvo apenas transcendencia en primer lugar por el repertorio que presentó como compositor, que no interesó al público francés (Scarlatti) y en segundo lugar, porque como intérprete tenía en 1905 una dura competencia con la propia colonia española afincada en París, empezando por sus amigos Ricardo Viñes y Joaquín Malats que triunfaban en las salas de conciertos. No obstante, las razones más significativas son que Granados no tenía el apoyo de grandes figuras musicales francesas, y que no había la necesidad de llenar el vacío que sí hubo en 1909 tras la desaparición de Albéniz. Granados hasta entonces no estaba dentro de los círculos musicales ni en círculos sociales parisinos y, por tanto, no tocaba en conciertos públicos o privados ni estaba en contacto con la sociedad musical

\footnotetext{
75 CLARK: Enrique Granados. Poet... op. cit., p. 125.

${ }^{76}$ LADMIRAULT, Paul. "Festival Granados". Revue Musicale SIM. 15 de abril de 1914.
} 
francesa ni internacional. Su relación con Francia, que habían comenzado muy tímidamente en 1905, despega definitivamente en 1909. Granados es desconocido u obviado hasta 1909 en la prensa francesa, momento en que se pone las esperanzas sobre él como el futuro musical "español" confirmado en su concierto de 1911; y es a partir de 1911 cuando sus relaciones con la contemporaneidad musical internacional se reflejan en una rica relación epistolar, hasta entonces inexistente.

Otro de los puntos importantes de esta cuestión es, como ya se ha comentado, el fallecimiento del carismático compositor Albéniz en 1909. Granados se deja presentar en la prensa como compositor, creando una expectación sobre su obra y sobre su propia persona como futuro de la música española. No parece casual que justo entonces nuestro compositor decidiera comenzar sus Goyescas, cuando el mundo francés buscaba en él un sustituto del compositor gerundés. Granados compone entonces una suite pianística al estilo albeniciano aunque personalísimo en la forma y en el fondo.

En 1911 Granados cumple las expectativas puestas en él mediante la presentación su obra, que aunque incluye a Scarlatti y su Allegro de concierto la mayor parte del programa está limitado a un repertorio "exportable” en Francia: los Azulejos, que vinculan a Granados directamente con Albéniz, dos Danzas y las Goyescas. Evidentemente la repercusión y el impacto crítico de estas últimas fue mucho mayor que el resto de las obras del programa, unas por ya conocidas, otras simplemente porque no interesan al mundo musical francés, que demanda de un compositor español música "española", aunque en el caso de Granados fuera "innovadora", "el estilo moderno español"77, recogiendo el testigo como representante de la música española a pesar de que exista ya una innegable realidad musical en la propia capital francesa. Apenas se discuten las características de su música. Las Goyescas ante todo se consideran "españolas", se hace una descripción de su argumento y se felicitan por el descubrimiento del nuevo compositor español, sin apenas entrar en más disquisiciones.

Las críticas de 1914 ya entran en cuestiones de tipo estético y estilístico. La modernidad de Granados se mide en el nuevo concepto de música española vinculado a Castilla en contraposición a Albéniz y a su vinculación con la música histórica española,

${ }^{77}$ GUERILLOT, F. Revue musical mensuelle SIM. 15 de abril de 1911. P. 89. 
sobre todo a través de las Tonadillas, mostrando una modernidad española alejada de las “castañuelas” y el orientalismo que predominó en el siglo XIX.

Aunque Granados en 1914 es impulsado por la SMI, lo que evidentemente era favorable para dicha sociedad, con Vuillermoz, también parece cierto que Granados no entra en ninguno de los dos bandos que en ese momento partían a la sociedad musical parisina. Le Monde Musical escribe también una elogiosa crítica y en el número del 30 de junio le dedica un artículo y la portada de la revista. Por otro lado, el hecho de que Fauré lo invitase a formar parte del jurado Diémer hace que retome o comience relaciones con pianistas prestigiosos contemporáneos, además de que, según consta en las cartas recibidas tras su muerte por la Ilustración Musical Hispano-Americana figuras tan distantes en pensamiento estético musical como D’Indy, Fauré, Saint-Saëns o Debussy le dedican elogiosos comentarios.

La presentación de Goyescas en París es, sin duda, el origen de su fama como compositor universal. El repertorio que le dio la fama será el que perdure en el tiempo y el que se interprete y acepte mundialmente, (Danzas, Goyescas y Tonadillas) incluyendo su propio país de origen, España, a pesar de sus esfuerzos por presentar y difundir música alejada de los patrones españolistas ${ }^{78}$.

El hecho de que Granados fuese considerado un "hijo" de la escuela francesa de piano a través de sus estudios con De Bériot favoreció el proceso de "acogimiento" de Granados por la sociedad musical francesa. Apadrinado por Saint-Saëns y posiblemente Fauré, algunos compositores utilizaron su figura y sobre todo su trágica muerte para enarbolar la bandera francesa con fines políticos. D'Indy en su carta de condolencia muestra su antigermanismo a través de Granados:

\footnotetext{
“Quería mucho a Enrique Granados y estoy triste por saber que no lo veré más. Ya un gran número de nuestros artistas franceses ha sucumbido gloriosamente en esta lucha épica de nuestra bella civilización latina contra la pesada barbarie germánica. Y estos allí cumplieron bien su deber dando su vida por Francia. (...) creo bien que nuestros amigos de España estarán con nosotros en el momento del ajuste de cuentas final de todas las infamias teutonas” Carta de V. D’Indy. París, 14 de abril de 1916
}

\footnotetext{
${ }^{78}$ En el mismo concierto que presentó las Goyescas en Barcelona también estrenó el Cant de les estrelles, obra en catalán para piano, órgano y coro editada por la Naxos gracias a la recuperación de la partitura y su edición por Douglas Riva en la editorial Boileau y su interpretación y grabación por la Naxos. También sus esfuerzos por la difusión de su Dante son llamativos en este sentido: el 25 de mayo de 1915 en el Palau la Sinfónica de Madrid interpretó Dante y el 5 y 6 de noviembre de 1915 la orquesta Sinfónica de Chicago había hecho el estreno americano de Dante con la solista contralto Sophie Breslau, contralto de la compañía del Metropolitan.
} 
También Collet a la hora de valorar su obra lírica quiere justificar el evidente wagnerismo (lo que equivaldría a decir "germanismo") de Granados con términos de guerra, tal como "la ofensiva musical germánica, victoriosa en la península como en las otras naciones europeas (...)"79, de forma que también otras naciones estaban bajo el influjo de Wagner. Así parece que Granados fue adoptado por la nación francesa como “ahijado francés", utilizando su vinculación a Francia no sólo en el aspecto musical sino también político ${ }^{80}$.

${ }^{79}$ COLLET: Albéniz et Granados... op. cit., p. 216.

${ }^{80}$ Seguimos la tesis de Samuel Llano, El hispanismo y la cultura musical de París: 1898-1931, leída en 2007 en el departamento de Historia del Arte III de la Universidad Complutense de Madrid. 